\title{
SECOND INTERNATIONAL CONFERENCE ON HEMORHEOLOGY UNIVERSITY OF HEIDELBERG, 27 JULY- 1 AUGUST, 1969
}

THE GREATER part of this current number of Biorheology is devoted to Summaries of the work of this Conference. The Proceedings will be published in full in book form in 1970. The Conference Chairman was Professor H. Hartert. The Honorary Chairman was Professor G. Quadbeck, Institute für Pathochemie und Allgemeine Neurochemie, Universität Heidelberg.

The Conference, held under the auspices of the University of Heidelberg was comprised of the Inaugural Session on July 28th, several working sessions on each day of the Conference from Monday, July 28th, to and including Friday, August 1st, at which sixtyeight original scientific contributions were presented, and the Closing Session. At the Inaugural Session Welcome Addresses were given by Professor G. Quadbeck on behalf of the host, the University of Heidelberg, and by the President of the International Society of Hemorheology, Professor A. L. Copley and by the Conference Chairman, Professor H. Hartert.

There was a varied social programme, including wine tasting and a Supper in a vine dressers wine-shop in the Palatinate; a reception by the Lord Mayor of Heidelberg in the big barrel cellar of the city's castle; a boat trip on the Neckar River to Hirschhorn Castle; a classical concert in the yard of Heidelberg castle and a banquet in the Stiftsmuhle near Heidelberg, in the Neckar valley. There was also a separate social programme for the ladies attending the conference.

\section{SPONSORS}

Major sources of financial aid were Knoll AG, Chemische Fabriken, Ludwigshafen/RH; Pharmacia Laboratories, Uppsala Sweden; Hoechst-Behring, Frankfurt/Main-Mannheim; Farbenfabriken Bayer AG, Leverkusen; Gebruder Guilini GMBH, Ludwigshafen/RH; Johann A. Wülfing, Düsseldorf; Ciba AG, Basel; and Nattermann, Arzneimittel, KölnBraunsfeld. 



\section{THE INTERNATIONAL SOCIETY OF HEMORHEOLOGY}

\section{THE COUNCIL}

\section{(A) Officers}

President: Professor A. L. Copley (U.S.A.), Hemorrhage and Thrombosis Research Laboratories, VA Hospital, East Orange, New Jersey; and Department of Pharmacology, New York Medical College, New York.

Vice-Presidents: The Americas: Professor S. G. MAson (Canada), Department of Chemistry, McGill University, Montreal; Asia and Australia: Professor S. OKa (Japan), Department of Physics, Tokyo Metropolitan University Tokyo; Europe and Africa: Professor H. HARTERT (Germany), Staedtisches, Krankenhaus Kaiserslautern and Medizinische Fakultaet, Universitaet Heidelberg, Heidelberg.

Secretary: Professor G. Bugliarello (U.S.A.), Biotechnology Committee, CarnegieMellon University, Pittsburgh, Pennsylvania.

Treasurer: Professor S. WITTE (Germany), Diakonissenkrankenhaus, Karlsruhe-Rueppur, and University of Nürnberg-Erlangen, Erlangen.

\section{(B) Committee Chairmen}

(1) Blood Cellular Elements: Professor A. C. Burton, Department of Biophysics, University of Western Ontario, London, Canada; (2) Clinical Hemorheology: Professor R. Wells, Department of Medicine, Harvard Medical School and Peter Brent Brigham Hospital, Boston, Mass. 02115, U.S.A.; (3) Coagulation and Fibrinolysis: Professor K. M. Brinkhous, Department of Pathology, School of Medicine, University of North Carolina, Chapel Hill, N.C. U.S.A.; (4) Instrumentation: Professor H. Wayland, Division of Engineering and Applied Science, California Institute of Technology, Pasadena, California 91109, U.S.A.; (5) In vivo Hemorheology: Professor S. Rowlands, Department of Medical Biophysics, Faculty of Medicine, University of Calgary, Calgary, Alberta, Canada; (6) Link with Hemodynamics: Professor M. G. Taylor, Department of Physiology, University of Sydney, Sydney, N.S.W., Australia; (7) Model Studies and Extra Vivum Hemorheology: Professor A. Silberberg, Polymer Department, The Weizmann Institute of Science, Rehovoth, Israel; (8) Plasma Components and Modifiers: Dr. M. Joly, Service de Biophysique, Institut Pasteur, Paris, France; (9) Standards and Terminology: Dr. G. W. Scott Blair, Grist Cottage, Iffley, Oxford, England; (10) Theoretical Hemorheology: Professor R. L. Whitmore, Department of Mining and Metallurgical Engineering, University of Queensland, St. Lucia, Brisbane, Australia; (11) Vessel Wall Hemorheology: Professor C. A. Wiederhielm, Department of Physiology and Biophysics, University of Washington, Seattle, Washington, U.S.A. 